\title{
Ten Trees a Day: How learning science and a story of multilingual buffalo help students learn syntax
}

\author{
Lynn Santelmann*
}

\begin{abstract}
This paper describes an activity designed to help students improve skills in drawing syntax tree structures without significantly increasing instructor grading time. In this formative exercise, students draw ten trees prior to each class period, correct their own work, and reflect on their mistakes. This assignment incorporates many practices that research on learning suggests are essential for understanding and retention of material. In addition, this exercise incorporates some best practices on effective feedback. The activity works best when students understand the science behind it, so discussion of the pedagogical reasons for the exercise is essential. Further, overt discussion of how to learn helps students develop effective skills for learning linguistics. Self-correct homework assignments like this can be applied to many courses that involve learning skills or terminology.
\end{abstract}

Keywords. syntax; learning science; formative feedback; tree-drawing; skill learning

1. Introduction. This article presents an activity for an introductory, undergraduate syntax class designed to help students improve basic syntax skills so that they are better equipped to take part in classroom discussions and problem-solving group activities. It draws on insights from the literature on learning and cognitive science as well as insights from the literature on feedback practices to improve learning. The activity, called "Ten Trees a Day," developed when I applied literature about learning and memory to a long-standing problem with teaching syntax: Students struggle to draw trees quickly and accurately.

1.1. THE PROBLEM. One frequent request I received from students in syntax was for more practice in drawing trees, especially from students who were struggling to keep up in class discussions. I could tell that students were struggling because the wait time for students to draw trees was long and increased dramatically as we began to work with more complicated structures such as X-bar structures. The middle group of students could take three to five minutes to draw a moderately complicated tree, while the slowest group of students often quit trying when they could not keep up. The opportunities provided in class and in the textbook were not sufficient for students to gain facility with drawing trees. Even the accompanying workbook designed for students to practice, contained surprisingly few trees. For many years, I had wanted to add more practice for students but could find no way to accomplish this without also adding an unreasonable grading burden.

1.2. THE CONTEXT. The course is a basic ten-week introduction to generative syntax and fulfills a requirement for undergraduate majors. I teach at an urban, access university where thirty-seven percent of the students are first generation college students, thirty-six percent are minorities, and the average age of undergraduate students is twenty-five (Student Profile 2021). The students bring a rich, varied set of life experiences to the classroom and mixed backgrounds in terms of

\footnotetext{
* Many thanks to the organizers of the LSA Symposium on Scholarly Teaching, in particular Kazuko Hiramatsu and Michal Temkin Martinez, for developing a forum to share ideas about scholarly teaching. Thanks also to my many syntax students who have gamely followed my buffalo in their tree-drawing adventures, pointed out my errors, and provided feedback on the exercises. Author: Lynn Santelmann, Portland State University (santelmannl@pdx.edu).
} 
college preparation. To help foster a more equitable classroom, I have begun to examine my teaching for areas where I make unwarranted assumptions about the skills students enter with.

2. Insights from learning science and effective pedagogical practices. When I looked for a solution to help my students learn skills for tree drawing, I first drew on research on memory and learning. In addition, I wanted students to view this as a learning exercise rather than a test, so I looked to literature on formative feedback.

2.1. INSIGHTS FROM MEMORY AND LEARNING. One thing that became clear as I met with students who struggled with linguistics was that few had strategies for learning and practicing material. Further, these skills are not often explicitly taught in high school or early college.

Given this knowledge, I looked to literature in psychology and cognitive science for practices I could use to help students learn and retain material. Much of the literature is summarized in Brown, Roediger III, and McDaniel's (2014) book Make it stick: The science of successful learning. These findings indicate that successful learning practices involve the following:

- retrieving new information from memory either via testing or self-quizzing (e.g., Roediger III and Butler 2011; Arnold and McDermott 2013)

- spaced retrieval practice, that is retrieval over larger periods of time rather than focused practice all at one time (e.g., Cepeda et al. 2006);

- interleaved practice or practice with different types of examples mixed together (e.g., Rohrer, Dedrick, and Stershic 2015);

- generating an answer to a question before being shown the answer (e.g., Jacoby 1978; Slamecka and Graf 1978);

- reflection on what has been learned and on how the learning process has worked (e.g., Boud, Keogh, and Walker 1996; May and Etkina 2002).

Thus, in designing an activity for students to gain fluency in drawing syntax trees, I wanted to include practice generating and retrieving information, space the practice with varied kinds of tree structures, and give students a chance to reflect on and discuss the structures.

2.2. INSIGHTS FROM RESEARCH ON FORMATIVE FEEDBACK. The activity also needed to address the grading issue and students' overall apprehension and frustration during the course. I chose to design the assignments as a formative assessment that could help both the instructor and the students see how students were performing. Formative assessments are part of effective feedback because they involve the student in the assessment process (Black et al. 2003; Nicol and Macfarlane-Dick 2006). In addition, according to Nicol and Macfarlane-Dick (2006), good feedback has the following characteristics:

- it clarifies what good performance is;

- it facilitates self-assessment;

- it encourages dialogue around learning;

- it provides opportunities to bridge the gap between current and desired performance;

- it provides information that can shape teaching.

3. The solution: Self-correct homework. The solution for providing syntax students with more practice and more effective feedback came through adapting self-correct homework, a practice I already used in other courses that required mastery of technical skills, most notably History of English and Introduction to Linguistics. For example, in the History of English, I give the students a set of Old English words and students use information on sound changes between Old 
and Middle English to determine each word's pronunciation in Middle English. Students complete the exercises at home and bring their answers to class. In class, students discuss their work with their peers and then we discuss the answers and remaining questions as students correct their original homework. Students receive full credit for bringing the completed exercise to class and clearly marking corrections.

Self-correct homework uses several features of effective learning and good feedback. In terms of learning, it requires students to retrieve information and generate their own answers. The types of problems can be interleaved so students must retrieve information while they generate the answers. Furthermore, as students discuss their answers, there is time for reflection and clarification of misunderstandings. In terms of feedback, students are involved in the assessment, can compare their performance to the target, and have a chance for dialogue.

4. Adapting self-correct homework for syntax: Ten Trees a Day. While self-correct homework worked well for some topics, syntax has more content than tree drawing, and I needed to adapt this activity to make it work for syntax. The adaptations are relatively simple: Students receive sentences and the answers, instead of receiving just the problems. They correct their answers at home by circling their errors, redrawing the trees they got wrong, and briefly describing the error. We begin each class with a brief discussion of any questions. The next ten sentences are then released after class.

4.1. Ten TREes a Day: Design FeATURES. Several features were designed into this activity to use the insights from learning science. The first was releasing only ten sentences after each class which forces students into spaced practice. The second was to vary the structures of the sentences within each day's trees to provide interleaved practice. The third design feature was requiring students to redraw the tree and to describe what they did wrong. This step requires students to examine their work carefully and reflect on where they are making errors.

The activity also has a fourth, originally unintentional design feature that adds both variety and increases student interest. As generating random sentences is difficult, I began to craft a narrative to make generating sentences easier. Searching for inspiration, I spotted Buffy the buffalo (from Buffalo) on my desk. Buffy got a new identity as a young adventurer and soon I began ending each day's sentences on a mild cliff-hanger. When the class covered verb movement, Buffy found a Welsh identity as Gwilym and met another multilingual buffalo. The light-hearted, somewhat absurd narrative provides interest and light relief which relieves some of the anxiety around the course.

Example sentences are given in (1) below. These sentences contain a variety of structures, including transitive and intransitive verbs, complements and adjuncts, possessives, subordinate clauses, and a sentential subject.

(1) a. The two buffalo walked underneath the magnificent foliage.

b. The sun was beginning to slowly set behind the bluffs.

c. Wilhelmina trotted forward in eager anticipation of their journey's end.

d. Gwilym lumbered behind her wondering what the significance of the wisteria was.

e. Wilhelmina suddenly bellowed a panicked cry.

f. For Wilhelmina to bellow so loudly meant danger.

g. Gwilym's heart began to race as he galloped to meet Wilhelmina.

h. "What scared you so badly?"

i. The buffalos' panic grew as their eyes adjusted to the growing darkness.

j. An enormous snarling wolf blocked the path under the wisteria. 
This day's trees were given toward the end of the term just as I was introducing wh-movement, so they contained one subordinate clause with wh-movement. The other sentences were crafted to review many of the structures we had covered earlier. ${ }^{1}$

4.2. TEN TREeS A DAY USES LEARNING SCIENCE AND GOOD FEEDBACK PRACTICES. This exercise contains many of the same practices that self-correct homework does in my other classes. Students receive spaced, interleaved practice and generate their own answers. They are directly involved in the assessment process as they correct their answers, rework sentences they get wrong, and reflect on the errors. There is additional reflection during class when we discuss the day's trees. Students receive immediate feedback because they have access to the answers. Because the students get the sentences and the answers at the same time' they have agency in how they complete the exercise. Some students prefer to draw all the trees and then check them, others draw a single tree, check it, then draw the next.

4.3. Benefits From using Ten Trees a Day. After I implemented Ten Trees a Day, I observed a number of benefits. Students' facility with tree drawing improved as demonstrated by the fact that the wait time for students to draw a structure in class has decreased considerably. Tree drawing has become proceduralized by most students, which reduces their cognitive load. This reduction in cognitive load makes it possible for more students to participate in class discussions and activities. A colleague who has adopted this exercise has made similar observations.

The formative nature of the assignments with student correcting their own work also normalizes mistakes. Students see themselves and their peers making mistakes. This normalization of errors shifts focus from the correct answer to the process of learning and reduces student anxiety.

The fact that students are turning in something during each class period also means instructors can quickly assess both individual and group understanding of the concepts we are covering. Individual students who are struggling are easily identified before the first summative assessment is due and we can meet for remediation, if necessary. For the class as a whole, unclear concepts are either brought up by students or I notice them in patterns of repeated errors.

Finally, my grading time has not significantly increased. I glance through each assignment looking for patterns and checking to see that students marked their corrections and redrew trees they got wrong. The one or two sentences that describe any errors or any questions that students write on their papers take very little time to read.

\subsection{UNEXPECTED BENEFITS FROM TEN TREES A DAY. In addition to the hoped-for pedagogical} benefits, I discovered some unexpected benefits while using this assignment. The first is that students get enough practice drawing trees that I do not need to include many trees on summative assessments. Summative assessments can focus instead more on argumentation and analysis of data, which are the higher-level goals for the course.

After using Ten Trees a Day over several terms, I noticed that I was seeing implicit learning. The narrative often resulted in my using structures that we had not yet covered in class. For example, infinitive clauses occur fairly early in the narrative. Inevitably, students ask about these and we discuss the possible analysis options. Then when we reach null categories such as PRO

\footnotetext{
${ }^{1}$ The full Ten Trees a Day story can be found at https://ingscholarlyteaching.files.wordpress.com/2021/01/10-treesa-day-buffalo-story.pdf, under the 2021 Organized Session on the webpage for Scholarly Teaching in Linguistics: https://lingscholarlyteaching.wordpress.com.
} 
or traces, students grasp the need for these devices more readily because they have seen and used these structures earlier.

5. Broader applications for self-correct homework. Ten Trees a Day is one example of a practice that uses features from learning science that are known to foster student learning. Selfcorrect homework can be applied to increase learning and retention in any course where students need to learn or practice skills. Self-correct assignments further facilitate students taking ownership of their own learning and involve students in the feedback process.

When using an activity with repeated practice such as Ten Trees a Day, it is important to discuss the science behind the assignments. If students understand that repeated, distributed, interleaved practice with reflection increases learning and that making mistakes is expected and necessary, they respond positively to the assignment. As the term progresses, they can see the relationship to their own learning. If they do not understand the reasons behind the assignment, such practice feels like busywork.

Developing an explicit understanding of the learning process, the role of mistakes, and the role of practice is especially important for non-traditional students. Many non-traditional students feel they do not fit in. When they make mistakes or do not understand, they see themselves as being alone in making errors and question whether they belong. At the same time, many students from all backgrounds do not realize that making mistakes is a normal part of learning. Seeing others make mistakes and hearing others ask for explanations demonstrates that mistakes are common and can help traditional and non-traditional students see they fit in.

I encourage instructors to look for ways to teach explicit skills for practice and retention of material, and to use low-stakes, formative feedback where students are involved in the feedback process. Such teaching practices not only help students learn class material better, they also develop skills that all students can take on to other courses. Helping students focus on how to learn in addition to what to learn helps students from all backgrounds succeed.

\section{References}

Arnold, Kathleen M. \& Kathleen B. McDermott. 2013. Test-potentiated learning: Distinguishing between the direct and indirect effects of tests. Journal of Experimental Psychology: Learning, Memory, and Cognition 39. 940-945. https://doi.org/10.1037/a0029199.

Boud, David, Rosemary Keogh \& David Walker. 1996. Promoting reflection in learning: A model. In Richard Edwards, Ann Hanson \& Peter Raggatt (eds.), Boundaries of adult learning, 32-56. London: Routledge.

Brown, Peter C., Henry L. Roediger III, \& Mark A. McDaniel. 2014. Make it stick: The science of successful learning. Cambridge, MA: Harvard University Press.

Cepeda, Nicholas J., Harold Pashler, Edward Vul, John T. Wixted, \& Doug Rohrer. 2006. Distributed practice in verbal recall tasks: A review and quantitative synthesis. Psychological Bulletin 132(3). 354-380. https://doi.org/10.1037/0033-2909.132.3.354.

Jacoby, Larry L. 1978. On interpreting the effects of repetition: Solving a problem versus remembering a solution. Journal of Verbal Learning and Verbal Behavior 17. 649-667.

May, D. B. \& Eugenia Etkina. 2002. College physics students' epistemological self-reflection and its relationship to conceptual learning. American Journal of Physics 70(12). 1249-1258. https://doi.org/10.1119/1.1503377.

Nicol, David J. \& Debra Macfarlane-Dick. 2006. Formative assessment and self-regulated learning: A model and seven principles of good feedback practice. Studies in Higher Education 31(2). 199-218. https://doi.org/10.1080/03075070600572090. 
Roediger III, Harry L. \& Andrew C. Butler. 2011. The critical role of retrieval practice in longterm retention. Trends in Cognitive Sciences 15(1). 20-27. https://doi.org/10.1016/j.tics.2010.09.003.

Rohrer, Doug, Robert F. Dedrick \& Sandra Stershic. 2015. Interleaved practice improves mathematics learning. Journal of Educational Psychology 107(3). 900-908. https://doi.org/10.1037/edu0000001.

Slamecka, Norman J. \& Peter Graf. 1978. The generation effect: Delineation of a phenomenon. Journal of Experimental Psychology: Human Learning \& Memory 4(6). 592-604. https://doi.org/10.1037/0278-7393.4.6.592.

Student Profile. 2021. Portland State University. [Web page]. https://www.pdx.edu/researchplanning/student-profile. 